tetrazolium/formazan assay for cell growth assays in culture. Cancer Commun. 3:207-212.

20.Kreith, F. 2001. Principles of Heat Transfer. Brooks/Cole, Pacific Grove, CA.

21.Dally, J.W. 1990. Packaging of Electronics Systems: A Mechanical Engineering Approach. McGraw-Hill, New York.

22.Kaliberov, S., M.A. Stackhouse, L. Kaliberova, T. Zhou, and D.J. Buchsbaum. 2004. Enhanced apoptosis following treatment with TRA-8 anti-human DR5 monoclonal antibody and overexpression of exogenous Bax in human glioma cells. Gene Ther. 11:658-667.
Received 26 February 2004; accepted 19 March 2004.

Address correspondence to Yiqun G. Shellman, Department of Dermatology, University of Colorado Health Science Center, Denver, CO 80262, USA. e-mail: Yiqun. Shellman@uchsc.edu

\title{
Western blot analysis of Src kinase assays using peptide substrates ligated to a carrier protein
}

\author{
Jie Xu, Luo Sun, Inca Ghosh, and Ming-Qun Xu \\ New England Biolabs, Beverly, MA, USA
}

BioTechniques 36:976-981 (June 2004)

We have applied intein-mediated peptide ligation (IPL) to the use of peptide substrates for kinase assays and subsequent Western blot analysis. IPL allows for the efficient ligation of a synthetic peptide with an $N$-terminal cysteine residue to an intein-generated carrier protein containing a cysteine reactive $C$-terminal thioester through a native peptide bond. A distinct advantage of this procedure is that each carrier protein molecule ligates only one peptide, ensuring that the ligation product forms a sharp band on sodium dodecyl sulfate polyacrylamide gel electrophoresis (SDS-PAGE). We demonstrate the effectiveness of this approach by mutational analysis of peptide substrates derived from human cyclin-dependent kinase, Cdc2, which contains a phosphorylation site of human c-Src protein tyrosine kinase.

\section{INTRODUCTION}

Protein phosphorylation plays a pivotal role in many signal transduction pathways $(1,2)$. Yet the dissection of kinase signaling pathways presents a challenge to existing techniques (3). The use of synthetic peptide substrates has become a powerful tool to determine kinase specificities, allowing mutational analysis and investigation into optimal phosphorylation sites (4). One extensively used technique for kinase activity assessment is the measurement of the incorporation of radiolabeled $\gamma$-phosphate from ATP (5). An alternate approach for the detection of protein phosphorylation is to determine the immunoreactivity of a protein to a phosphor-specific antibody that recognizes the phosphorylated epitopes within proteins (6). Two common methods for the determination of im- munoreactivity are enzyme-linked immunosorbent assay (ELISA) and Western blot analysis. Because of the small size of synthetic peptides, typically in the range of 10-20 amino acid residues, they are not suitable for Western immunoblotting analysis.

In this report, we describe an easy and effective method for producing carrier protein-peptide ligation products for kinase assays and subsequent Western blot analysis. A peptide possessing a phosphorylation site of interest is first synthesized with an aminoterminal cysteine residue. The peptide is then ligated to the cysteine-reactive carboxyl terminus of a carrier protein via a peptide bond by intein-mediated protein ligation (Figure 1) (7-9). This results in the ligation product migrating as a single band on a sodium dodecyl sulfate (SDS) polyacrylamide gel.

\section{MATERIALS AND METHODS}

\section{Generation of Peptides and Carrier Protein}

All peptides were synthesized with an N-terminal cysteine and purified by high-performance liquid chromatography (HPLC) (New England Biolabs, Beverly, MA, USA) (Table 1; References 10 and 11). For ligation to the peptides, the paramyosin $\Delta$ Sal fragment from Dirofilaria immitis (12) was expressed as a paramyosin-inteinchitin binding domain fusion protein (PXB) and purified on chitin resin. Intein-mediated cleavage was carried out at $4^{\circ} \mathrm{C}$ for $16 \mathrm{~h}$ by incubation of the chitin resin in column buffer containing $20 \mathrm{mM}$ Tris- $\mathrm{HCl}, \mathrm{pH} 8.5,0.5 \mathrm{M} \mathrm{NaCl}$, and $50 \mathrm{mM}$ 2-mercaptoethanesulfonic acid (MESNA; Sigma, St. Louis, MO, USA). Protein elutions were collected in 5-mL fractions from the column, and protein concentrations were determined by Bradford assay (13).

\section{Ligation of Carrier Protein and Peptide}

For the experiment shown in Figure 2 , the ligation reactions were performed overnight at $4{ }^{\circ} \mathrm{C}$ in a $100-\mu \mathrm{L}$ reaction volume with $500 \mu \mathrm{M}$ of peptide and $20 \mu \mathrm{M}$ of paramyosin carrier protein in the presence of $100 \mathrm{mM}$ Tris- $\mathrm{HCl}, \mathrm{pH} 8.5$, and $10 \mathrm{mM}$ MESNA. For the experiment shown in Figure 3 , the ligation reactions were carried out as described above except for a shorter ligation time $\left(4 \mathrm{~h}\right.$ at $\left.4^{\circ} \mathrm{C}\right)$ and an increase in peptide concentration to $1 \mathrm{mM}$ final concentration.

\section{Kinase Assays}

The ligated samples were dialyzed against $5 \mathrm{mM}$ Tris- $\mathrm{HCl}, \mathrm{pH} 7.5,50 \mathrm{mM}$ $\mathrm{NaCl}$ to remove the unligated peptide using a $0.025 \mu \mathrm{m}$ filter (Millipore, Bedford, MA, USA). Kinase assays were carried out at $30^{\circ} \mathrm{C}$ for $60 \mathrm{~min}$ in a 10 $\mu \mathrm{L}$ reaction with each sample containing $10 \mu \mathrm{M}$ (or $0.30 \mathrm{mg} / \mathrm{mL}$ ) of the carrier protein and 12.5 U Src kinase (Upstate, Lake Placid, NY, USA) in the presence of $100 \mu \mathrm{M}$ ATP and $25 \mathrm{mM}$ Tris- $\mathrm{HCl}$, $\mathrm{pH} 7.2,31.25 \mathrm{mM} \mathrm{MgCl}_{2}, 25 \mathrm{mM}$ $\mathrm{MnCl}_{2}, 0.5 \mathrm{mM}$ ethylene glycol-bis(2- 
aminoethylether)-N,N, $\mathrm{N}^{\prime}, \mathrm{N}^{\prime}$-tetraacetic acid, and $0.5 \mathrm{mM}$ dithiothreitol.

\section{Western Blot Analysis}

Western immunoblotting analysis was performed using an anti-phosphotyrosine antibody (P-Tyr-100; Cell Signaling Technology, Beverly, MA, USA). Each kinase assay sample was diluted 21-fold into an SDS-containing loading buffer. The samples were heated to $95^{\circ} \mathrm{C}$ for $5 \mathrm{~min}$ before an aliquot $(10 \mu \mathrm{L})$ of each assay sample was loaded onto a $12 \%$ Tris-glycine poly-

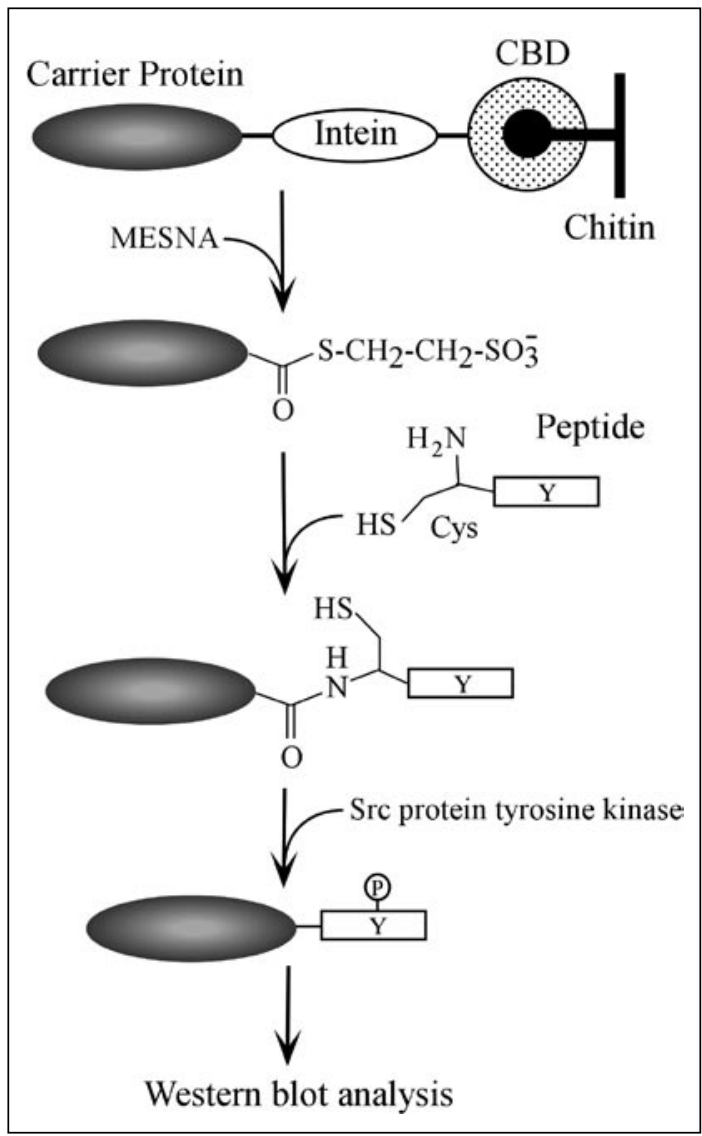

Figure 1. Ligation of carrier protein and peptide substrate. A carrier protein is fused to the $\mathrm{N}$ terminus of a modified intein-chitin-binding domain (CBD) tag. The three-part fusion protein is expressed in Escherichia coli and purified on chitin resin. Intein-mediated cleavage is induced by the addition of 2-mercaptoethanesulfonic acid (MESNA), resulting in the release of the carrier protein possessing a cysteine-reactive C-terminal thioester (7). Ligation of this carrier protein to a synthetic peptide containing an $\mathrm{N}$-terminal cysteine results in a native peptide bond between the two reacting species. The ligated carrier protein-peptide product serves as substrate for Src kinase assays and subsequent Western blot analysis with phospho-tyrosine antibody. Phosphorylation of a tyrosine residue $(\mathrm{Y})$ in the peptide sequence yields a positive signal. The circled $\mathrm{P}$ indicates a phospho group. acrylamide gel (Invitrogen, Carlsbad, CA, USA). Proteins were resolved by ectrophoresis in SDS-containing runbuffer. Proteins were transferred and then buffered saline, $\mathrm{pH} 7.5,0.2 \%$ Tween $^{\circledR}$ $20,0.05 \%$ Triton $\left.{ }^{\circledR} \mathrm{X}-100\right)$ supplemented with $5 \%$ nonfat dry milk at $25^{\circ} \mathrm{C}$ for $1 \mathrm{~h}$. The membrane was probed with the primary antibody (P-Tyr-100) prepared by 1:5000 dilution in TBSTT supplemented with $2 \%$ nonfat dry milk. After an overnight incubation at $4{ }^{\circ} \mathrm{C}$, the membrane was washed three times with TBSTT and incubated with a horseradish peroxidase (HRP)-linked anti-mouse immunoglobulin $\mathrm{G}$ ( $\mathrm{IgG})$ antibody (1:5000 dilution in TBSTT with $2 \%$ dry milk) at room temperature for $1 \mathrm{~h}$, followed by three additional 15-min washes in TBSTT. Antibody binding was then detected by chemiluminescence with the Phototope ${ }^{\circledR}$ HRP Western Blot Detection System (Cell Signaling Technology). The membrane was further incubated with a rabbit anti-paramyosin antibody (produced by Covance Research Products, Danver, PA, USA). Detection was performed with the PhototopeHRP Western Blot Detection System.

\section{RESULTS AND DISCUSSION}

We have designed a series of peptides that are derived from the substrates of human c-Src protein tyrosine kinase (Src-PTK) possessing an additional N-terminal cysteine residue (Table 1). The peptide Src-Y contains the optimal sequence predicted for the Src kinase (4). The Cdc2-Y15 peptide is a substrate for $\mathrm{Src}$ PTK corresponding to $\mathrm{I}^{10}$ to $\mathrm{K}^{20}$ of human cyclin-dependent kinase, Cdc2 (10). Mutational study indicates that phosphorylation at $\mathrm{Tyr}^{15}$ on
Table 1. Peptide Substrates

\begin{tabular}{|ll|}
\hline Peptide & Sequence \\
\hline Src-Ya & CAEEEIYGEFEA \\
Cdc2-pY15 & CIGEGTpYGVVYK \\
Cdc2-Y15 & CIGEGTYGVVYK \\
Cdc2-E12K & CIGKGTYGVVYK \\
Cdc2-G13K & CIGEKTYGVVYK \\
Cdc2-T14K & CIGEGKYGVVYK \\
Cdc2-Y15F & CIGEGTFGVVYK \\
Cdc2-G16F & CIGEGTYFVVYK \\
Cdc2-V18E & CIGEGTYGVEYK \\
Cdc2-Y19F & CIGEGTYGVVFK \\
aAccording to Reference 4. \\
bAccording to References 10 and 11. \\
\hline
\end{tabular}

$\mathrm{Cdc} 2$ has a regulatory role in the cell cycle (11). To evaluate whether this technique can be applied to the investigation of the effect of mutations surrounding a phosphorylation site, single amino acid substitutions were introduced at six different positions (Table 1). Also included were a phosphorylated peptide (Cdc2-pY15) and a negative control peptide (Cdc2-Y15F) with $\mathrm{Tyr}^{15}$ substituted with phenylalanine residue.

A 27-kDa carrier protein, paramyo$\sin \Delta$ Sal fragment from $D$. immitis (12) was produced according to the method described previously (8). The paramyosin protein was expressed as a tripartite fusion protein consisting of the paramyosin protein segment, which is fused at its $\mathrm{C}$ terminus to the $\mathrm{N}$ terminus of the Mycobacterium xenopi GyrA intein (22 kDa), followed by a chitin-binding domain (CBD; $7 \mathrm{kDa}$ ) from Bacillus circulans. Intein-mediated cleavage was induced by incubation of chitinbound fusion protein with MESNA, resulting in the release of paramyosin carrier protein possessing a carboxylterminal thioester group.

The carrier protein was ligated to six different substrates or control peptides. The ligation reactions were performed overnight at $4^{\circ} \mathrm{C}$ with $500 \mu \mathrm{M}$ peptide and $20 \mu \mathrm{M}$ carrier protein. Proteins were resolved by electrophoresis on a $12 \%$ SDS polyacrylamide gel (Figure 2A). The covalent linkage of peptide to the carrier protein caused a mobility shift on on sodium dodecyl sulfate polyacrylamide gel electrophoresis (SDS-PAGE). Since the stoichiometry of this ligation reaction is precisely 
one-to-one, each paramyosin-peptide ligation product formed a single sharp band. The extent of ligation is indicated by the ratio of the ligated (or shifted band) and unligated paramyosin carrier proteins. Figure $2 \mathrm{~A}$ shows that the lowest ligation efficiency, of approximately $50 \%$, was observed for Cdc2pY15 (lane 3) and Src-Y (lane 4) and is likely due to their poor solubility. The other Cdc2-derived peptides exhibited approximately $80 \%-90 \%$ ligation efficiency.

Next, the ligated samples were dialyzed to remove the unligated peptide. Kinase assays were carried out at $30^{\circ} \mathrm{C}$ for $60 \mathrm{~min}$, with each sample contain- ing $10 \mu \mathrm{M}$ (or $0.30 \mathrm{mg} / \mathrm{mL}$ ) of the carrier protein and $12.5 \mathrm{U}$ Src kinase in the presence of $100 \mu \mathrm{M}$ ATP. Western blot analysis was performed using an anti-phospho-tyrosine monoclonal antibody that recognizes peptides containing phosphotyrosine. Figure 2B reveals that Src-Y, Cdc2-Y15, and Cdc2-Y19F (lanes 2-4) peptides exhibited positive signals comparable to the control Cdc2pY15 (lane 1),

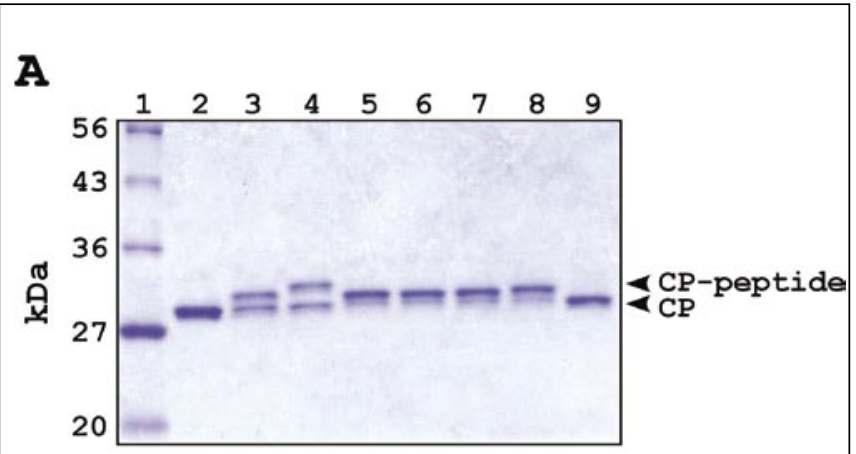

B

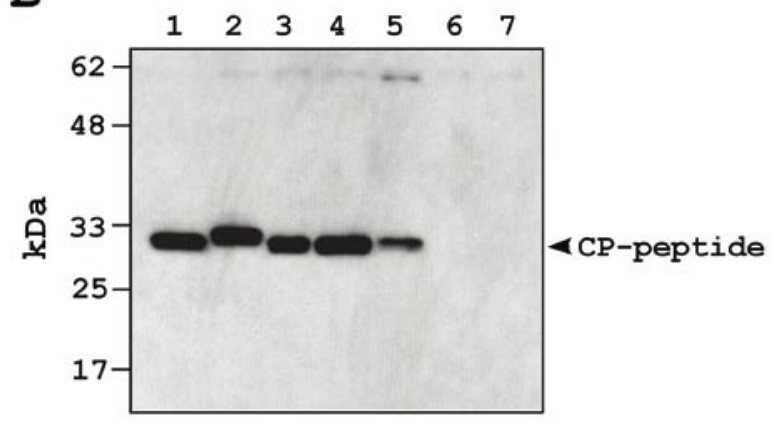

Figure 2. Generation of carrier protein-peptide substrates and Src kinase assays. (A) Ligation of paramyosin carrier protein and various peptide substrates examined by Coomassie Blue stained sodium dodecyl sulfate polyacrylamide gel electrophoresis (SDS-PAGE). The samples were resolved by electrophoresis on a $12 \%$ Tris-glycine polyacylamide gel under denaturing conditions. Lane 1, protein marker (Broad Range; New England Biolabs); lanes 2 and 9, paramyosin carrier protein $(\mathrm{CP} ; 27 \mathrm{kDa})$; lane 3, CP-Cdc2pY15; lane 4, CP-Src-Y; lane 5, CP-Cdc2-Y15; lane 6, CP-Cdc2-Y19F; lane 7, CP-Cdc2-Y15F; lane 8, CP-Cdc2-G13K. The formation of a paramyosinpeptide ligation product (CP-peptide) caused a mobility shift observed in lanes 3-8 compared to the unligated carrier protein. (B) Western blot analysis of Src kinase assays with phospho-tyrosine antibody. The assays were performed using the dialyzed substrates after ligation of paramyosin to: lane 1, Cdc2-pY15; lane 2, Src-Y; lane 3, Cdc2-Y15; lane 4, Cdc2-Y19F; lane 5, Cdc2-G13K; or lane 6, Cdc2-Y15F. Lane 7 contains only paramyosin. Phosphorylation of the ligated peptide substrates (as indicated by the arrow) was detected in lanes 2-5. Protein markers are indicated on the left side. Cdc2, cyclin-dependent kinase.

which contains a phosphorylated tyrosine residue. As expected, the mutation of Tyr15 in Cdc2-Y15F resulted in no detectable signal. Cdc2-G13K exhibited a significant reduction in signal, suggesting that this substitution

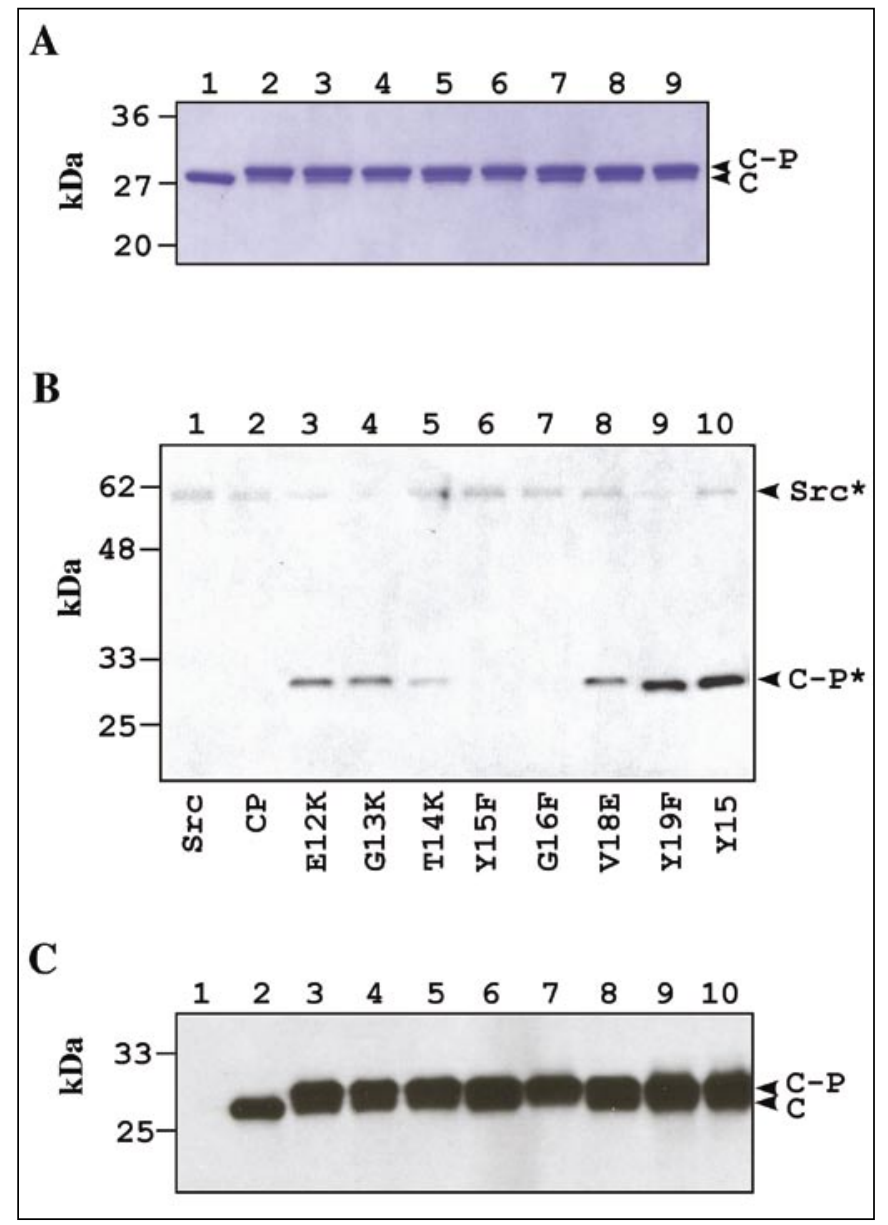

Figure 3. Mutational analysis of various peptide substrates. The kinase assays were carried out using the ligation samples, without a dialysis step, in a final concentration of $250 \mu \mathrm{M}$ peptide, $5 \mu \mathrm{M}$ carrier protein, $100 \mu \mathrm{M}$ ATP 12.5 U Src kinase, and $1 \times$ Src Kinase Reaction Buffer (Upstate). (A) Sodium dodecyl sulfate polyacrylamide gel electrophoresis (SDS-PAGE; $12 \%$ ) of ligation reactions stained with Coomassie Blue. Lane 1 contains paramyosin; lanes 2-9 contain paramyosin ligated to various peptides, Cdc2-E12K (lane 2), Cdc2-G13K (lane 3), Cdc2-T14K (lane 4), Cdc2-Y15F (lane 5), Cdc2G16F (lane 6), Cdc2-V18E (lane 7), Cdc2-Y19F (lane 8), or Cdc2-Y15 (lane 9). Arrows indicate ligated and unligated proteins. (B) Western blot analysis of kinase assays. The paramyosin was ligated to various peptides carrying single amino acid mutation (as indicated below the blot). The assay samples were resolved by SDS-PAGE (12\%). Western blot analysis was incubated with phospho-tyrosine antibody. Lane 1, Src kinase alone (Src); lane 2, paramyosin (CP); lanes 3-10 contain paramyosin ligated to Cdc2-E12K (lane 3), Cdc2G13K (lane 4), Cdc2-T14K (lane 5), Cdc2-Y15F (lane 6), Cdc2-G16F (lane 7), Cdc2-V18E (lane 8), Cdc2-Y19F (lane 9), or Cdc2-Y15 (lane 10). Arrow at $60 \mathrm{kDa}$ indicates Src autophosphorylation signal, and arrow at approximately $29 \mathrm{kDa}$ shows positive signals of peptide substrates. (C) The Western blot was analyzed with a paramyosin antibody. Arrows indicate the presence of unligated and ligated protein species at 27 and $29 \mathrm{kDa}$, respectively. Cdc2, cyclin-dependent kinase. C, carrier protein; C-P, carrier protein-peptide; Src*, autophosphorylated Src kinase; C-P*, phosphorylated carrier protein-peptide. 
significantly affected the efficiency of Src-mediated phosphorylation at Tyr15. The presence of a weak signal at $60 \mathrm{kDa}$ in each lane is likely due to autophosphorylation of the Src kinase as previously reported (14). To detect any significant protein loading variations, the membrane was incubated with a rabbit anti-paramyosin antibody, following the first immunoassay with the anti-phospho-tyrosine antibody. The results confirmed the presence of similar amounts of paramyosin carrier protein in all lanes (data not shown).

Furthermore, we sought to analyze the entire set of mutant peptide substrates (Table 1). The ligation reactions were performed according to the procedure described above, except for a shorter ligation time $\left(4 \mathrm{~h}\right.$ at $\left.4^{\circ} \mathrm{C}\right)$ and an increase in peptide concentration to $1 \mathrm{mM}$ final concentration. The ligation efficiencies were in the range of $70 \%$ $90 \%$ as evaluated by Coomassie ${ }^{\circledR}$ Bluestained SDS-PAGE (Figure 3A). The kinase assays were performed directly using the ligation samples containing $250 \mu \mathrm{M}$ peptide and $5 \mu \mathrm{M}$ carrier protein. The assays were examined by Western blot analysis reacted with the anti-phospho-tyrosine antibody (Figure 3B). The data suggests that mutation of the amino acid residues in proximity to $\mathrm{Tyr}^{15}$ as shown in the $\mathrm{T} 14 \mathrm{~K}$ or G16F substitution almost completely blocked phosphorylation by Src kinase, whereas the substitution of E12, G13, and V18 had significant but reduced effects compared to the T14K and G16F substrates. In addition, autophosphorylation of Src kinase was detected by the presence of a signal at $60 \mathrm{kDa}$ in all the samples including the control with Src kinase alone (in the absence of the substrate). Finally, the Western blot was reacted with the rabbit anti-paramyosin antibody to verify the approximate quantity of carrier proteins in each lane (Figure 3C).

In conclusion, we have developed a sensitive method for kinase assays by ligating a peptide substrate via its $\mathrm{N}$ terminal cysteine residue to the $\mathrm{C}$ terminus of a paramyosin carrier protein. This approach allows for the examination of kinase activity using small synthetic peptide substrates by Western immunoblotting analysis. The procedure is convenient and involves only minimum chemical manipulation (with MESNA), which permits use in most laboratories. Thioester-tagged carrier proteins of different sizes can be readily purified using commercially available intein vectors $(7,8)$. The ligation efficiency can be evaluated based on a mobility shift on SDS-PAGE. Since the ligation is usually conducted with a 25- to 50-fold molar excess of synthetic peptide, the purity of a peptide sample does not significantly influence the yield of the ligation product. One significant advantage is that this method does not depend on the use of radiolabeled ATP or the addition of basic residues to the peptide, as required for binding to phosphocellulose paper (5). The carrier-peptide substrates can be utilized for semiquantitative analysis (6). Furthermore, the signal from kinase autophosphorylation is distinguishable from that of a substrate as long as a carrier of different size is chosen. Recently, we have conducted the assay of a peptide substrate of Abl protein tyrosine kinase using paramyosin as the carrier (data not shown). Thus, the method presented may be applied to other enzymatic assays for the study of protein modification. However, this technique relies on the availability of highly specific antibodies, such as anti-phospho-tyrosine antibody. This approach can yield direct evidence of kinase and cognate substrates and has the potential utility in the screening of optimal sequences.

\section{ACKNOWLEDGMENTS}

The authors thank Drs. Thomas $C$. Evans, Jr., Nicole M. Nichols, and Eric Cantor for their critical reading of the manuscript and Guillaume Lesage for technical assistance. We also thank New England Biolabs Organic Division for peptide synthesis and Dr. Donald G. Comb for his support.

\section{REFERENCES}

1.Hunter, T. and W. Eckhart. 2004. The discovery of tyrosine phosphorylation: it's all in the buffer! Cell 116:35-39.

2.Hunter, T. 1994. 1001 protein kinases reduxtowards 2000. Semin. Cell Biol. 5:367-376.

3.Shokat, K.M. 1995. Tyrosine kinases: modu- lar signaling enzymes with tunable specificities. Chem. Biol. 2:509-514.

4.Songyang, Z., K.L. Carraway III, M.J. Eck, S.C. Harrison, R.A. Feldman, M. Mohammadi, J. Schlessinger, S.R. Hubbard, et al. 1995. Catalytic specificity of protein-tyrosine kinase is critical for selective signaling. Nature 373:536-539.

5.Hardie, D.G. 2000. Protein Phosphorylation: A Practical Approach. Oxford University Press, New York.

6.Rijksen, G., B.A. van Oirschot, and G.E.J. Staal. 1991. Nonradioactive assays of protein-tyrosine kinase activity using anti-phosphotyrosine antibodies. Methods Enzymol. 200:98-107.

7.Evans, Jr., T.C., J. Benner, and M.-Q. Xu. 1998. Semisynthesis of cytotoxic proteins using a modified protein splicing element. Protein Sci. 7:2256-2264.

8.Evans, Jr., T.C. and M.-Q. Xu. 1999. Inteinmediated protein ligation: harnessing nature's escape artists. Biopolymers 51:333-342.

9.Muir, T.W., D. Sondhi, and P.A. Cole. 1998. Expressed protein ligation: a general method for protein engineering. Proc. Natl. Acad. Sci. USA 95:6705-6710.

10.Lew, D.J. and S. Kornbluth. 1996. Regulatory roles of cyclin dependent kinase phosphorylation in cell cycle control. Curr. Opin. Cell Biol. 8:795-804.

11.Fletcher, L., Y. Cheng, and R.J. Muschel. 2002. Abolishment of the Tyr-15 inhibitory phosphorylation site on $\mathrm{Cdc} 2$ reduces the radiation-induced $\mathrm{G}_{2}$ delay, revealing a potential checkpoint in early mitosis. Cancer Res. 62:241-250.

12.Limberger, R.J. and L.A. McReynolds. 1990. Filarial paramyosin: cDNA sequences from Dirofilaria immitis and Onchocerca volvulus. Mol. Biochem. Parasitol. 38:271-280.

13.Bradford, M.M. 1976. A rapid and sensitive method for the quantitation of microgram quantities of protein utilizing the principle of protein-dye binding. Anal. Biochem. 72:248254.

14.Draetta, G., H. Piwnica-Worms, D. Morrison, B. Druker, T. Roberts, and D. Beach. 1988. Human Cdc2 protein kinase is a major cell-cycle regulated tyrosine kinase substrate. Nature 336:738-744.

Received 10 February 2004; accepted 5 April 2004.

Address correspondence to Dr. Ming-Qun $X u$, New England Biolabs, Inc., 32 Tozer Road, Beverly, MA 01915, USA. e-mail: xum@neb.com 